\title{
IMPORTANCE OF GUIDED FINE NEEDLE ASPIRATION CYTOLOGY (FNAC) FOR THE DIAGNOSTICS OF THYROID NODULES - OWN EXPERIENCE
}

\author{
A. Martínek ${ }^{\mathrm{a}}$ J. Dvořáčkováb ${ }^{b}$, M. Honka ${ }^{\mathrm{a}}, \mathrm{J}$. Horáček ${ }^{\mathrm{c}}$, P. Klvaña ${ }^{\mathrm{a}}$ \\ a Department of Internal Medicine, University Hospital, Ostrava, Czech Republic \\ - CGB Laboratory, Ostrava \\ c Department of Pathology, Medico-Social Faculty, University of Ostrava.e-mail: arnost.martinek@fnspo.cz
}

Received: April 5, 2004; Accepted: June 10, 2004

Key words: Thyroid neoplasms/Fine needle aspiration cytology/Ultrasound guidance

The aim of our study was to assess the accuracy and limitations of ultrasound guided fine-needle aspiration cytology ( FNAC) of thyroid nodules.

Methods: The usg-FNAC results of 245 patients with thyroid nodules, who afterwards underwent thyroid surgery or who died, and autopsies were carried out, and compared retrospectively with cytologic results. Patients with malignant cytologic conclusion without histological confirmation after surgery or autopsy were excluded from the study ( 9 persons). The usg-FNAC results were divided as follows: group 1: diagnosis of malignancy $(\mathrm{n}=30)$, group 2: suspicion of malignancy $(n=28)$, group 3: benign $(n=126)$, group 4: inconclusive $(n=29)$.

Results: Assuming the cytologic results of group 1 and group 2 were interpreted as being malignant and those of group 3 as being benign, the sensitivity, specificity and accuracy of usg-FNAC were $90 \%, 85 \%$ and $86 \%$ respectively. Comparing the cytologic conclusions between a group of patients with follicular lesions and a subgroup of other lesions a statistically significant difference $(p<0,01)$ between both subgroups using Fisher's test was found. Sensitivity, specificity and diagnostic accuracy in subgroup of follicular lesions were low $(71 \%, 63 \%, 67 \%)$, while in the subgroup of other lesions were high $(94 \%, 86 \%, 88 \%)$. FNAC can specify the nature of focal lesion with high sensitivity, specificity and diagnostic accuracy in the cases of non-follicular lesions. Histological evaluation is required to specification of the nature in cases in which cytology is indicative of follicular proliferation.

\section{INTRODUCTION}

Ultrasound examination of thyroid gland and the neck region is a basic diagnostic imaging method providing information on structure of parenchyma of thyroid gland, on its relationship to its surroundings and on regional lymph nodes ${ }^{4}$.

Though the method of thyroid gland ultrasound developed greatly in the recent years (high-frequency B-mode sonography, colour-power Doppler), it is not reliable enough for the diagnostics of malignant focal lesions ${ }^{15,17,19}$.

On that account this method is often accompanied by cytological examination of found lesions. Material is obtained by fine needle aspiration biopsy under ultrasound guidance (FNAC).

Contribution of FNAC for determination of etiology of found lesions depends on clinician experience to collect of samples, cytopathologist experience to assess the samples ${ }^{10}$ and nature of found lesion ${ }^{3}$. The aim of this report is to present the analysis of our results of cytologic examination of focal lesions of thyroid gland in a group of our patients in 1986-2002 and comparison with the literature.

\section{MATERIALS AND METHODS}

In the period 1986-2002 we performed 781 fine needle aspiration cytology of thyroid nodules under ultrasound guidance ( further FNAC) on 245 persons at the Department of Internal Medicine, Faculty Hosp. Ostrava. The puncture had to be repeated on 92 persons ( $38 \%$ of the group) during their second visit. The evaluated group consisted of men ( $21 \%$ ) of the average age of 65.9 years (46-82 years) and women ( $79 \%$ ) of the average age of 59 years (13-87 years).

Interventional ultrasound of the thyroid gland was performed under ultrasound guidance on the devices MEDATA 600, supplied by the firm ATL, and SONOLAYER SSH- 140 A, supplied by Toshiba, with the use of the 7.5 $\mathrm{MHz}$ probe, 22-gauge needles, $20 \mathrm{ml}$ syringes and syringe pistols. Jodisol solution was used as local disinfection and Elolipid was used as a contact-medium between the tisssue and the transducer during FNAC. The operation was carried out without local anaesthesia. The obtained material was used for the preparation of smears. Particles of material were fixed by $10 \%$ solution of formalin. Liquid material was processed by the cytospin technique.

Indication for puncture were focal lesions of the thyroid of uncertain origin recognised by ultrasound. Contraindication was non-compliance or haemorrhagic 
diathesis. Definite benign diagnosis was confirmed during long-term observation in most cases. Definite malignant diagnosis was confirmed in 41 persons $(73 \%)$ by histologic examination of the resected material, in 15 persons ( $27 \%$ ) by autopsy. People with a malignant cytologic finding which was not confirmed by any of the mentioned methods were not included in the evaluated group ( 9 persons).

\section{RESULTS}

In our study out of the total number of 245 examined persons with focal lesions in thyroid gland, benign disease (Table 1) was found in 189 cases $(77 \%)$. Malignant disease (Table 2) was found in 56 cases (23\%) - 44 women and 12 men.

The cytologic sample was adequate in 165 examined persons $(87 \%)$ with benign lesions and 48 examined persons $(86 \%)$ with malignant lesions. The diagnostic rate of adequacy $86 \%$ and $87 \%$ was reached in 153 cases during the first session, while in 92 cases the puncture had to be repeated. The number of sessions was between 1 and 3 , with an average of 1,5 examinations per person, the number of passess per session was 2-4, with an average of 3,3 punctures per person. Most of the punctured malignant foci were lesions larger than $1 \mathrm{~cm}$ ( 52 cases), and in 4 cases the malignant lesion was smaller than $1 \mathrm{~cm}$ in diameter (microcarcinoma).

Concordance (with definitive diagnosis) in the determination of a malignant disease and its further specification (Table 3) was reached in 36 cases (75\%), and also concordance in the determination of a benign disease was reached in 122 cases ( $74 \%$ ). Unambiguous cytologic malignant conclusions in 26 cases and suspicions of malignancy in 10 cases were considered as a concordance in the determination of malignancy.

Cytological evaluation (Table 1, 2) from the viewpoint of biologic behavior (benign x malignant) was inconclusive in 29 cases $(14 \%)$
The cytological evaluation was false negative as benign in 4 cases $(8 \%)$. Two cases were later diagnosed as follicular carcinoma and another 2 cases as papillary carcinoma.

The cytologic evaluation was false-positive as malignant in 4 cases and as suspicion for malignancy in 18 cases. This is a total of 22 cases 18 cases were later diagnosed as benign nodular goitre, 3 cases as benign follicular lesion and 1 case as oncocyte benign lesion.

The contribution of FNAC for specification of the etiology of thyroid gland lesions is presented in tables 1 and 2. The reason for sample inadequacy was insufficient amount of representative material. The conclusions of uncertain biologic behavior were indicated as lesions of uncertain biological character.

In the evaluated group of 213 persons with adequate aspirates, there were 48 patients with a malignant disease of thyroid gland and 165 patients with benign findings. In the malignant disease group, 13 cases were malignant follicular lesions (12x follicular carcinoma, 1x lymphoma), and the remaining 35 cases were: $28 x$ papillary thyroid carcinoma, $5 x$ anaplastic thyroid carcinoma, and 2 cases of breast carcinoma metastasis. The evaluated group of 213 people was further divided into two groups: a group with follicular lesion which consisted of 26 people (13x malignant diesase, 13 benign follicular proliferation), and a group with other lesions of the thyroid gland which consisted of 187 people (35x malign lesion and $152 \mathrm{x}$ benign lesion) - table 3 .

In the group of follicular lesions, the finding was correctly confirmed as positive in 5 cases $(38 \%)$, while cytologic evaluation was correctly confirmed as negative for malignancy in 5 cases ( $38 \%$ ). Cytological evaluation of uncertain biologic character was 11 out of 26 cases. The cytological conclusions were false-negative for malignancy in 2 cases $(15 \%)$. The cytological conclusion was falsepositive in 3 cases $(23 \%)$.

In the group of other lesions the finding was correctly positive in 31 out of 35 cases ( $89 \%)$, correctly negative for malignancy in 117 cases ( $77 \%$ ). The cytological evaluation

Table 1. Cytologic conclusion in the subgroup of patients with benign disease of the thyroid (number of patients).

\begin{tabular}{|l|c|c|c|c|c|c|}
\cline { 2 - 7 } \multicolumn{1}{c|}{} & $\begin{array}{c}\text { diagnosis of } \\
\text { malignancy }\end{array}$ & $\begin{array}{c}\text { suspicion of } \\
\text { malignancy }\end{array}$ & benign & inconclusive & inadequate & $\begin{array}{c}\text { total } \\
\text { (adequate) }\end{array}$ \\
\hline nodular goitre & 3 & 15 & 114 & 14 & 19 & $165(146)$ \\
\hline epiderm. cyst & - & - & 1 & - & 1 & $2(1)$ \\
\hline abscess & - & - & 1 & - & 3 & $1(1)$ \\
\hline benign follic. roliferation & 1 & 2 & 5 & 5 & 1 & $5(13)$ \\
\hline benign oncocytoma & 0 & 1 & 1 & 2 & 21 & $189(165)$ \\
\hline total & 4 & 18 & 122 & & 24 & $16(4)$ \\
\hline
\end{tabular}

Nondiagnostic reports and inconclusive reports were encountered among negative results except for sensitivity, specificity and diagnostic accuracy 
Table 2. Cytologic conclusion in the subgroup of patients with malignant disease of the thyroid (number of patients).

\begin{tabular}{|l|c|c|c|c|c|c|}
\cline { 2 - 7 } \multicolumn{1}{c|}{} & $\begin{array}{c}\text { diagnosis of } \\
\text { malignancy }\end{array}$ & $\begin{array}{c}\text { suspicion of } \\
\text { malignancy }\end{array}$ & benign & inconclusive & inadequate & $\begin{array}{c}\text { total } \\
\text { (adequate) }\end{array}$ \\
\hline follicular TC & 2 & 2 & 2 & 6 & 2 & $14(12)$ \\
\hline oncocytic TC & - & - & - & - & 1 & $1(0)$ \\
\hline papillary TC & 19 & 6 & 2 & 1 & 1 & $31(28)$ \\
\hline anaplastic TC & 2 & 2 & 0 & - & 1 & $1(0)$ \\
\hline medullary TC & - & - & - & - & - & $2(2)$ \\
\hline metastasis & 2 & - & - & - & - & $1(1)$ \\
\hline lymphoma & 1 & - & - & 8 & 8 & $56(48)$ \\
\hline total & 26 & 10 & 4 & - & $-25)$ \\
\hline
\end{tabular}

$\mathrm{TC}=$ thyroid carcinoma metastasis $=$ metastasis of breast cancer

Nondiagnostic reports and inconclusive reports were encountered among negative results except for sensitivity, specificity and diagnostic accuracy.

Table 3. Comparison of cytologic conclusions with definitive diagnosis.

\begin{tabular}{|c|c|c|c|c|c|c|c|}
\hline & & $\begin{array}{c}\text { cytologic } \\
\text { malig. }\end{array}$ & susp. for mal. & $\begin{array}{c}\text { cytologic } \\
\text { benign }\end{array}$ & inconcl. & \multicolumn{2}{|c|}{ total } \\
\hline \multirow{2}{*}{$\begin{array}{l}\text { follicular } \\
\text { lesions }\end{array}$} & benign & 1 & 2 & 5 & 5 & 13 & \multirow{2}{*}{26} \\
\hline & malignant & 3 & 2 & 2 & 6 & 13 & \\
\hline \multirow{2}{*}{ others } & benign & 3 & 16 & 117 & 16 & 152 & \multirow{2}{*}{187} \\
\hline & malignant & 23 & 8 & 2 & 2 & 35 & \\
\hline \multirow{2}{*}{ total } & benign & 4 & 18 & 122 & 21 & 165 & \multirow{2}{*}{213} \\
\hline & malignant & 26 & 10 & 4 & 8 & 48 & \\
\hline
\end{tabular}

Inconclusive reports were encountered among negative results except for sensitivity, specificity and diagnostic accuracy.

of uncertain biologic character was in 18 out of 187 cases (10\%). The cytological conclusions were false-negative for malignancy in 2 cases (6\%). The cytological conclusion was false-positive in 19 cases $(13 \%)$.

Non serious complications of FNAC occurred in 9 out of 781 cases $(1.2 \%)$. Transient algesic reaction was observed in 6 cases. Neurotic reaction was observed in 3 cases. There were no serious or lethal complications.

\section{DISCUSSION}

FNAC is at present the fundamental method for evaluation of thyroid nodules. Examination of the material obtained by FNAC enables us not only to differentiate between benign and malignant processes, but in many cases also the specific nosotaxy of tumour. However, FNAC of thyroid nodules has also its limitations ${ }^{18}$.

First, adequate cytologic interpretation depends on correct detection of the location of the suspected lesion and on the aspiration technique. Wrong detection and poor aspiration techniques cause most of the false-negative reports.

Second, the most important limitation of thyroid cytology lies in the differential diagnostics of cellular follicular lesions. It is especially difficult to distinguish benign from malignant follicular neoplasms by cytologic evaluation, because the diagnosis of cancer depends on demonstration of vascular or capsular invasion. In the case of follicular lesion the cytologic examination concludes relatively often as follicular lesion of uncertain biological character ${ }^{2,13}$. 

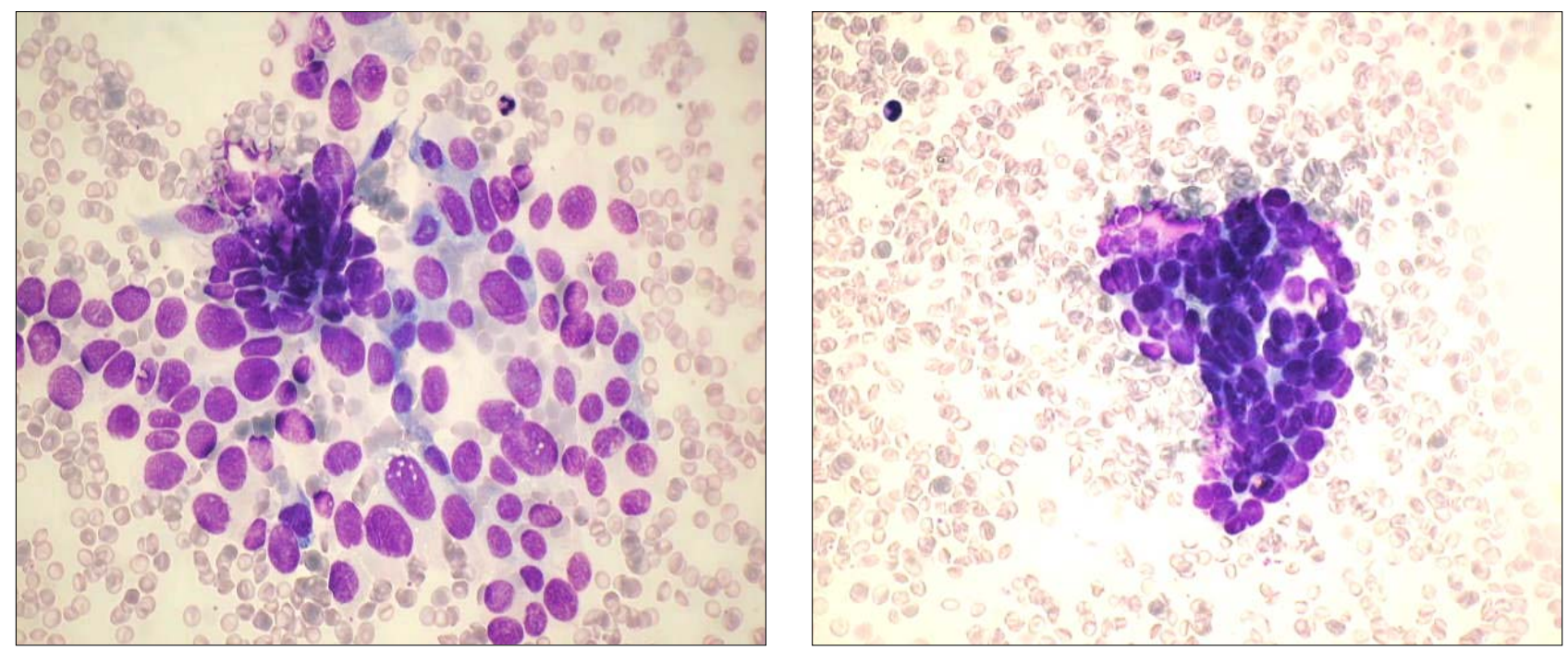

Fig. 1. Papillary thyroid carcinoma, MGG staining
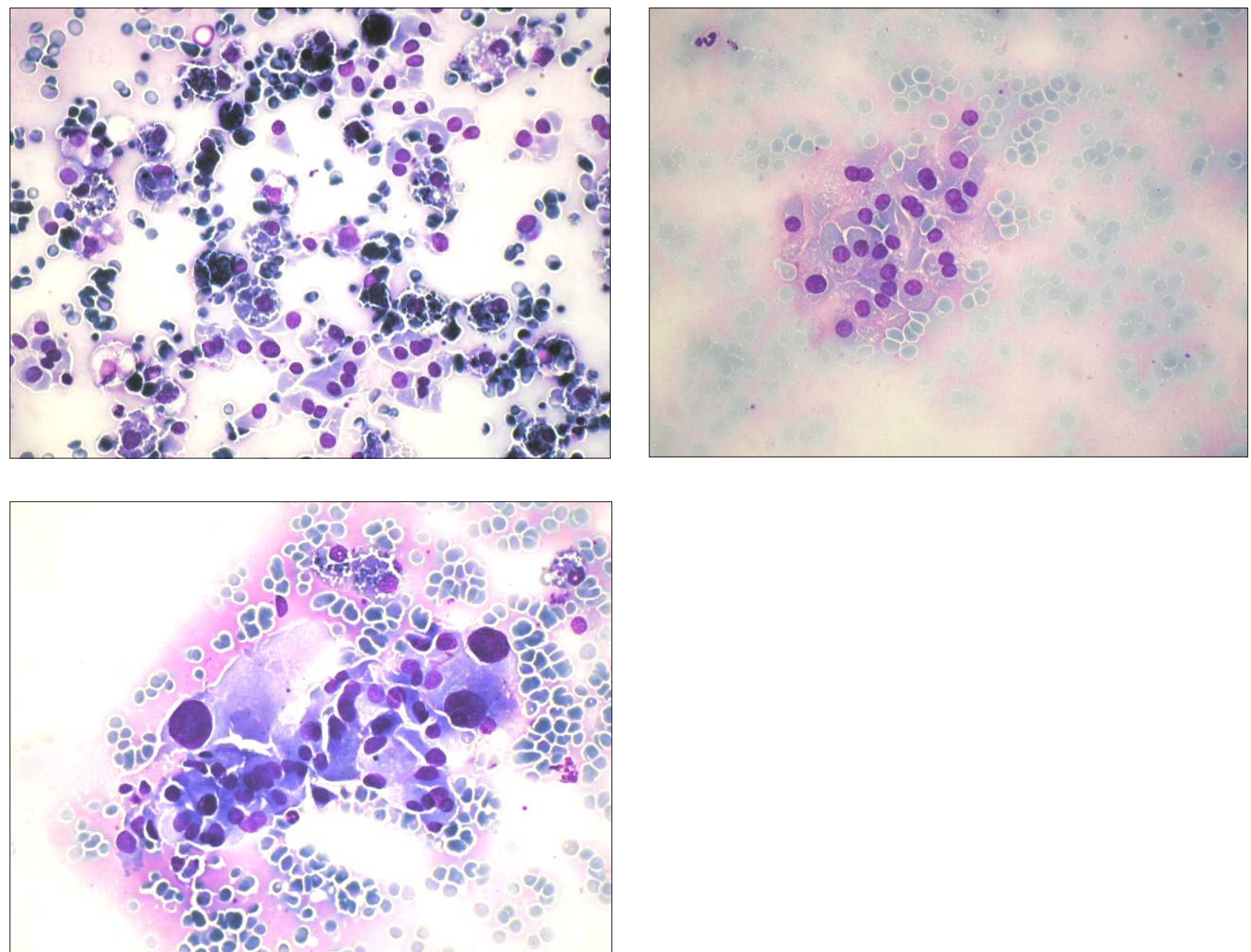

Fig. 2. Follicular thyroid carcinoma, MGG staining 
Adequacy for diagnosis in our subjects was in the range of the published success rate of $80-90 \%{ }^{7,14}$. In the group of benign lesions the rate of adequacy was $87 \%$, and in the group of malignant lesions $86 \%$. The majority of inadequate aspirates in accordance with the literature ${ }^{18}$ was due to a non-representative amount of the obtained material. Failure to provide an adequate specimen was not considered as a negative finding ${ }^{7}$, and the patients with inadequate specimen were continually observed.

The rate of malignant diseases in several large series varies in the range of $11,5 \%-35 \%$, , 12 . In our study, the rate of malignant diseases was found in the cited range, in particular in 56 cases, i.e. in $23 \%$ of all subjects. The occurrance of thyroid nodules was predominant in women in accordance with the literature, in particular in 149 women $(61 \%)$ of all patients and in 44 women $(78 \%)$ with the malignant disease of the thyroid. The most frequent finding in the group of benign lesions is multinodular goitre in accordance with the literature.

The most frequent finding in the group of malignant lesions is papillary TC - $54 \%$ of all malignant lesions and follicular TC $-27 \%$ of all malignant lesions ${ }^{9,16}$.

The rate of false-negative diagnoses determined by FNAC is published in the literature to be in range of $6.6-25.5 \%{ }^{16,20}$ and depends on the sucess rate of detection of malignant lesion and on the management of the technique of aspiration. The reason for the relatively low rate of false-negative diagnoses in our results could be the fact that the sampling was always done by the same team of two skillful physicians.

The published rate of false-positive diagnoses determined by FNAC is in range of $2-20 \%, 14,20$. The rate of false-positive diagnoses in our group (13\%) was within the range published in the literature.

The relatively high rate of false-positive diagnoses in our group of patients, which is nevertheless still in the range published in literature, may be due to the effort to determine the biologic behavior of the follicular lesions which were part of the group we evaluated.

Another explanation could be, that in the evaluated group, even the (suspicious aspirates) suspicions of malignancy are considered as a diagnosis of malignancy. The high rate of false-positive diagnoses as conclusion "suspicion of malignancy" has been presented by some researchers. Kountakis ${ }^{9}$ presented false-positive diagnoses in 5 out of 35 patients $(14 \%)$ in the category "diagnosis of malignancy", and in 4 out of 9 people ( $44 \%$ ) in the category "suspicion of malignancy". Caplan ${ }^{2}$ a Mikosch ${ }^{12}$ present an even larger difference. They present the rate of false-positive diagnoses in the range of $4-7 \%$ in the category of aspirates diagnostic of malignancy. In the category of conlusions "suspicion of malignancy", they present the rate of false-positive diagnoses in the range of $69-89 \%$.

In our group there were 4 false-positive diagnoses out of 30 cases ( $13 \%)$ in the category of aspirates diagnostic of malignancy. In the category of aspirates "suspicion of malignancy" there were 18 false-positive diagnoses from 28 specimens $(64 \%)$. The difference in rate of false-posi- tive diagnoses in the category of aspirates "diagnosis of malignancy" and "suspicion of malignancy" tested by the Fisher's factorial test ${ }^{1}$ are statistically significant $(\mathrm{p}=0.0001)$.

The number of cytological conclusions of uncertain biological character is presented in the range of $5 \%-19 \% 2,12,14$. In the evaluated group, the rate was $14 \%$. The relatively high rate could be explained the fact that some authors ${ }^{9}$ do not include follicular lesions with higher cytological uncertainty of biologic behavior into the evaluation of biologic behavior.

The majority of authors state ${ }^{4,8,12}$ that the decision on the biological character of a follicular lesion from the cytological smear obtained by FNAC is difficult. The reasons for these difficulties in decision are mentioned in the introduction to the discussion. The result is the relatively high rate of inconclusive diagnoses and low accuracy ${ }^{8,14}$. By contrast the contribution of FNAC is very high for the diagnostics of papillary and anaplastic $\mathrm{TC}^{11,12}$.

In the group of 26 patients with follicular lesion adequate for evaluation only a very low rate of correspondence in the case of malignancy or benignancy was reached. In both categories of biologic behavior the rate was only $38 \%$. By contrast in the remaining group of 187 patients, a high rate of correspondence in parameter malignancy ( $89 \%$ ) or benignancy ( $77 \%$ ) of the lesion was reached. The differences found evaluated by Fisher's test are of statistical significance $(\mathrm{p}<0.01)$.

In the group of patients with follicular lesions there was also a high rate of cytological conclusions of uncertain biological character ( $42 \%)$, while in the group of subjects with lesions of other etiology this rate was significantly lower $(10 \%)$. The found differences evaluated by Fisher's factorial test are of statistical significance. $(\mathrm{p}<0.01)$.

The obtained results confirm not only the difficulty of cytological evaluation of biologic behavior of follicular lesions (high rate of results with uncertain biologic behavior), but also the low rate of correspondence in cytological conclusions in the evaluation of biologic behavior ( low diagnostic accuracy).

Sensitivity of FNAC in the diagnosis of focal lesions of the thyroid is shown in the range $84-97 \% 6,8,9,12,16$. In the evaluated group of 184 subjects (after exlusion of 32 subjects with inadequate aspirates and 29 subjects with uncertain results of cytologic examination) the sensitivity was about $90 \%$ and in comparison with other researchers was in the lower part of the published range. Nevertheless after exclusion of group of patients with follicular lesions the sensitivity reached the upper part of the published range (94\%).

The specificity of FNAC in the diagnosis of focal lesions of the thyroid ranges from $60-87 \% 6,8,9,12$. In the evaluated group of 184 subjects on the condition of above mentioned limitation was the specificity $85 \%$. After exclusion of group of patients with follicular lesions reached the specificity $86 \%$.

Diagnostic accuracy of FNAC in the diagnostics of focal lesions of the thyroid is in the range of $69 \%$ - 
$87 \%{ }^{9,12,18}$. In the evaluated group of 184 subjects on the condition of above mentioned limitation there was the diagnostic accuracy relatively high $-86 \%$ and after exclusion of group of patients with follicular lesions with lower rate of diagnostic accuracy increased to $88 \%$.

FNAC in the diagnostics of focal lesions of the thyroid is considered as relatively safe method with low rate of complications. As one of the possible serious complications can be considered published implantation of malignant cells along the puncture canal. Occurence of this complication is very rare ${ }^{5}$.

In our set of 781 aspiration punctures only 9 non serious complications were observed, it means $1,2 \%$ of all punctures.

\section{CONCLUSION}

FNAC of focal lesions of the thyroid is a fundamental preoperative procedure. This method, with the exception of follicular lesions and published oncocyte lesions, can specify with a high rate of sensitivity, specificity and diagnostic accuracy the etiology of focal lesions of the thyroid. Follicular or oncocyte lesions verified by cytologic examination require specification of etiology - biological character - as distinct from other etiologies - by histologic examination. Relatively lower specificity of FNAC in the diagnosis of focal lesions of the thyroid can be caused by statistical significant higher occurrence of false-positive conclusions in the category "suspicion of malignancy" (in comparison with the category "diagnostic of malignancy”).

\section{REFERENCES}

1. Anděl J.: Statistické metody. Praha: MATFYZPRESS, 1998.

2. Caplan RH., Kisken WA., Strutt PJ., Wester SM (1991) Fine-needle aspiration biopsy of thyroid nodules, Thyroid nodule. Vol. 90, No. 1 July, Postgrad Med 90, 183-190.

3. Č́a J, Ryška A (2003): Aspirační cytologie štitné žlázy. Nucleus HK.

4. Dvořák J: Rakovina štítné žlázy. Nakladatelství Libri 1997 p. 104-107.
5. Franklin JA, Sheppard MC (1988) Thyroid nodules and thyroid cancer - diagnostic aspect. Bailleres Clin Endocrinol Metab 2, 761-775.

6. Chiu WY, Chia NH, Wan SK, Yuen CH, Cheung MT (1998) The investigation and management of thyroid nodules - a retrospective rewiev of 183 cases. Ann Acad. Med Singapore 27, 196-199.

7. Chow LS, Gharib H, Goellner JR, van Heerden JA (2001) Nondiagnostic thyroid fine-needle aspiration cytology: management dilemmas. Thyroid 12, 1147-1151.

8. Koike E, Yamashita H, Noguchi S and all (2001) Effect of combining ultrasonography ang ultrasound - guided fine-needle aspiration biopsy findings for the diagnosisof thyroid nodules. Eur J Surg Sep 167, 656-661.

9. Kountakis Stilianos E, Skoulas Ioannis G, Maillard AA (2002) The radiologic work-up in thyroid surgery: fine-needle biopsy versus scintigraphy and ultrasound. Ear. Nose. Throat. J. Mar 81, 151-154.

10. Límanová Z, Dušková J (1993) Diferenciální diagnostika strumy s pomocí tenkojehlové biopsie - rozdíly v dětské a dospělé populaci. Čs Pediat 48, 265-269.

11. Mačák J (1993) Karcinomy štítné žlázy z tzv. "tall cells”, Čs Patol 29, 9-10.

12. Mikosch P, Wartner U, Kresnik E and all (2001) Result of preoperative ultrasound guided fine needle aspiration biopsy of solitary thyroid nodules as compared with the histology. A retrospective analysis of 538 patients. Nuklearmedizin 40, 148-154.

13. Němec J. a kol.: Diagnostika chorob štítné žlázy. Praha: Avicenum, 1988.

14. Ogawa Y, Kato Y, Ikeda K, et all (2001) The value of ultrasoundguided fine-needle aspiration cytology fot thyroid nodules: an assessment of its diagnostic potential and pitfalls. Surg.Today 31, 97-101.

15. Papini E, Guglielmi R, Bianchini A, at all (2002) Risk of malignancy in nonpalpable thyroid nodules: predictive value of ultrasound and color-Doppler features. J Cli. Endocrino. Metab 87, 1941-1946.

16. Piraino P, Sepulveda A, Lillo R, Pineda P, Liberman C (2000) Cancer tiroideo.Comunicacion de 85 casos. Rev. Med. Chil. 128, 405-410.

17. Solbiati L, Osti V, Cova L, Tonolini M (2001) Ultrasound of thyroid, parathyroid glands and neck lymph. Nodes. Eur. Radiol. 11, 2411-2424.

18. Solymosi T, Toth GL, Bodo M (2001) Diagnostic accuracy of fine needle aspiration cytology of the thyroid: impact of ultrasonography and ultrasonographically guided aspiration. Acta Cytol 45, 669-674.

19. Vomáčka J, Michálková K, Dušková M, Hartlová M (1998) Ultrasonografická diagnostika maligních lézí štítné žlázy. Čes Radiol 52, 61-66.

20. Wilems JS, Lowhagen T (1981) Fine needle aspiration cytology in thyroid disease. Clin Endocrinol Metab 10, 247-66. 